\title{
Digital Environment and Socialisation of Adolescents with Reduced Somatic Health Status
}

\author{
Tatyana Shcherbakova ${ }^{1, *}$ and Elena Bespalova ${ }^{2}$ \\ ${ }^{1}$ Don state technical University, Gagarina Sq., 344003, Rostov-on-don, Russia \\ ${ }^{2}$ State-owned educational institution of the Rostov region «Rostov-on-Don sanatorium boarding \\ school», 36-line st., 58, 344025 Rostov-on-don, Russia
}

\begin{abstract}
The article discusses particularities, main resources and risks of socialization of adolescents with reduced somatic health status in the digital educational environment. The article highlights the features and psychological characteristics and determinants of socialisation success in the digital educational environment. The issues of psychological characteristics of adolescents with somatic health problems are considered. An insight is given into the specifics of adolescents with somatic problems adapting using the resources of the digital learning environment. The role of understanding the psychological portrait of adolescents with reduced somatic health status to support their successful adaptation to the digital environment was shown. The article shows the connection between the success of adolescents' socialisation and information competence, attitudes to interaction in the information space, achievement motivation and selfactualisation aspirations. The article describes the empirical study of psychological features of adolescents with reduced status of somatic health, shows their perceptions of limitations and risks of socialization. The material characterizing the specificity of self-concept and anxiety of adolescents with somatic problems, projection of these features in the space of interaction in the digital environment is presented.
\end{abstract}

\section{Introduction}

The dynamic transformation of the contemporary social situation in personal development has provoked a series of transformations that emphasize the state demand for the successful socialization of the young generation and increase the requirements for the system of their information competence development and the formation of a culture of safe behaviour in the digital environment. This is particularly relevant for children with reduced somatic health status, who find the digital environment to be a space of socialisation. An analysis of contemporary research by psychologists and sociologists and statistical data shows that there is a trend in modern society towards an increasing number of adolescents with certain somatic diseases, requiring some form of rehabilitation and a system of

\footnotetext{
*Corresponding author: tatiananik@list.ru
} 
psychological and pedagogical support to develop their constructive relationship with the social world and themselves [1-13]. Contemporary psychologists emphasise that the social development of a child with reduced somatic health status is qualitatively different from that of a normative child, and that the same social factors do not influence them identically in the course of socialization [3]. This is primarily due to the fact that somatic disease significantly changes the subject's entire social circumstances and to a certain extent alters his or her opportunities, and may lead to a restriction in the circle of contacts with the people around him or her. The use of the learning and information resources in the digital learning environment and its special features as a space for socialisation, self-presentation and primary career guidance for adolescents of this type are of particular importance here [4]. In addition, it is important to investigate and classify possible disruptions in the social development of an adolescent's personality caused by specific health conditions and their projections in the "adolescent-digital environment" relationship system.

Nowadays, psychology focuses on the issues of organizing a system to provide productive psychological support for the personal development of adolescents who are exposed to socialization risks. This allows for a new area of research into the possibilities of psychological support for adolescents' constructive activity in the context of the digital environment [1].

The works of Russian and foreign psychologists provide diverse perspectives on the etymology of constructive and destructive behaviour in adolescents with reduced somatic health status as a result of socialisation [2].

The assumptions that shape the self-esteem criteria of today's adolescents are constructed in the process of self-awareness. One of the developmental mechanisms, at this developmental stage, is the comparison of oneself to others: adults and peers, as well as famous past and present personalities and quasi-personalities, in the formation of selfknowledge and self-perception in the modern digital environment.

There is a correlation between adolescents' communication in virtual space and the formation of self-esteem, self-awareness, whose structural components are the parameters of attitude towards oneself and other people. [5].

In the context of peer relationships, the adolescent is included in a system of interaction built on the principles of psychological equality. Here the horizontal vector of relationships is realised, the moral norms of adult relationships - the norms of equality - are assimilated in the communication space with peers.

Contemporary psychological research has demonstrated that relationships with others are of great importance to the formation of an adolescent's personality; in fact, the developing subject's communication with others acts as a stimulating basis for personality development.

Both Russian and international psychologists have progressively expanded the idea that the socialisation of the subject takes place in the process of establishing multiple relationships with different environments. In modern science, the environment is described as a peculiar space of social activity and the realisation of the subject's system of relations, where social competence, social and emotional intelligence are formed. In this respect, the digital environment has an increasingly important place in the life of the developing subject [11-14].

Based on a large amount of empirical data, it has been argued that it is usually the unsatisfied sociogenic and other needs of adolescents that are the driving force behind conflict, demonstrative and aggressive behaviour.

Thus, the teenager's distorted view of the treatment he or she receives from those around him or her is reinforced, producing a kind of internal attitude that determines all of his or her further development. 
Together, these factors trigger negative emotions (frustration, resentment, anger, indignation, anger, rage) that lead to the development of deviant behaviour patterns. Experiencing these emotions leads to the teenager's need and desire to relieve and release mental tension. Having run all these actions through an 'internal filter', adolescents move on to developing a motivation to expand the scope of virtual communication and use other resources of the information space, where an immature personality risks becoming not only a successful user but also an object of manipulation. [9].

It is inherent in a developing individual's desire to gain the positive appraisal of those around him or her. Failure to fulfil this vital sociogenic need causes adolescents negative emotional feelings and forces them to seek a way out of the traumatic situation.

To clarify the set of factors that trigger various distortions in the socialisation patterns of adolescents with reduced somatic health status, it is important to understand the determinants of possible risks and their substantive and operational characteristics.

Modern educational psychology distinguishes between different types of relationships in inclusive education: advantaged, high-risk, disruptive [3]. An adolescent's personality develops well in a supportive environment where relationships between the adolescent and the surrounding adults and peers are predominantly built on an appropriate model. In a psychologically safe developmental environment, adolescents are more likely to engage in constructive interaction with the real world: the object world, image and character systems, nature, the social space and other people. A safe and healthy environment creates a psychological resource, a favourable environment for the formation of personality and the spiritual development of adolescents.

In an overly rigid and overly loyal environment, a young person with a disability may not feel comfortable enough, so it is important to build optimal psychologically and pedagogically appropriate relationships within the educational setting [10].

The adolescent faces many psychological challenges in modelling relationships with adults and peers, assimilating a set of moral and ethical principles, and developing and accepting a sense of social responsibility.

It is important to create a special atmosphere of safety and encouragement, practical activities create opportunities for the adolescent to develop life-affirming values and ideals, attitudes and social maturity.

The psychological mechanisms of socialisation in the microsociety are identification and reinforcement. During identification, adolescents consciously or unconsciously navigate towards an appropriate example and try to imitate others as a reference. The reinforcement mechanism purposefully, by means of upbringing, forms socially significant personal qualities in the child, a certain system of social skills, socially acceptable norms, principles and rules of behaviour necessary for successful functioning in society.

The most important aspect of the identification mechanism is that the digital educational environment and the information space in general, expose adolescents to different behaviours and values, as the key to their personal social experience. Thus, the identification mechanism in the process of adolescent socialization contributes to the formation of patterns relating to interaction with peers and adults, value orientations, worldview, communicative competence, as well as a certain image of the world and lifestyle.

It should be noted that the modern educational environment transformation is conditioned by the peculiarities of information society, diverse values and semantic space of society, availability of multicultural space, globalization of education in the conditions of transitional society.

A characteristic feature of adolescence is that an adolescent faces the choice of a model of relations with the world, moral norms and life values. This choice is a solution to a peculiar problem of meaning since the social space of an adolescent's life is politically 
normative: norms of school, family, religion, mass media, norms and values offered by social networks, a reference group, various youth subcultures. The internalisation of inadequate values can be a cause of deviation in the adolescent's socialisation.

Successful socialisation is based primarily on the acquisition of socially approved standards, norms and the internalisation of relevant ideas, values and attitudes by the individual.

In the process of socialisation a person gains experience in interacting with the world by reflecting on their attitudes and actions, assimilating typical interaction models communicated by others, as well as social stereotypes and attitudes adopted in the reference microenvironment.The individual, as a living being, forms an individual model of interaction with the world for themselves, indicating their own subjective living space and their own subjective position in relation to the world and everything that happens in it.

Based on the social environment's type and the emotional tone as well as the interaction networks in the information space, the adolescent-others relationship acquires certain characteristics and includes contextual factors that facilitate or hinder and inhibit development $[7,15]$.

Psychological research has shown that somatically challenged adolescents may have internal and external conflicts based on their own inferiority complex, didactogenia triggered, as a rule, by disorders in the system of relations with teachers and difficulty in perceiving educational material, something that should be taken into account when providing distance learning. To optimize the interaction of adolescents with reduced somatic health status it is important to take into account their specific characteristics and psychological peculiarities in comparison to a normative child.

\section{Methodology}

The following methodologies made up the diagnostic toolkit: method for studying selfconcept features (E. Pearce, D. Harris, A.M. Prikhozhan), method for multidimensional assessment of anxiety (L.I. Wasserman, E.E. Malikova). The study targeted adolescents enrolled in public schools and state-funded general education institutions of the Rostov Oblast for children in need of long-term treatment. Overall, the number of respondents was 244.

\section{Results}

The analysis of the diagnostic results showed different degrees of expression of the selfconcept components among adolescents living with somatic diseases. The students in the sanatorium school showed less self-confidence, a presence of doubt and internal conflict. They also demonstrated low self-esteem of popularity among their peers and their communication skills.

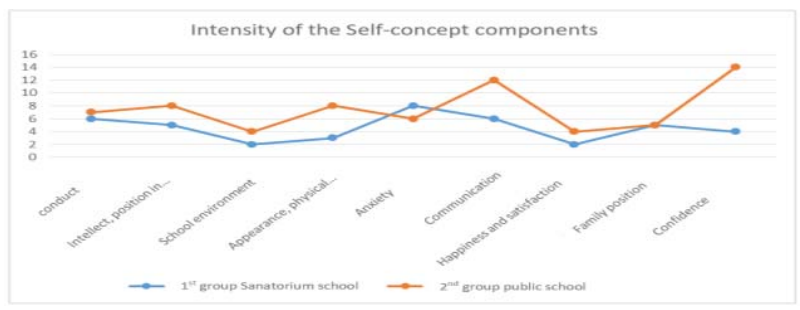

Fig. 1. Intensity of Self-concept components in groups of children attending a sanatorium school and a public school 
Differences are also observed in the expression of the scale relating to physical appearance and physical attractiveness. Since appearance is an important criteria of a person's self-presentation, and even more so for teenagers, the factor of physical development and acceptance of one's physical appearance becomes significant. Often sick children are quite sensitive about their appearance and have certain difficulties that affect their popularity among their peers. Adolescents in public schools ranked on the borderline of average and high.

Both groups of young people showed realistic attitudes towards their behaviour. They felt that in principle they met the expectations of adults. The results are also identical on the "Family life" scale, with young people showing general satisfaction with their position in the family.

Adolescents living in residential care show higher levels of anxiety, tension and frustration compared to their peers living in families and studying in public schools.

Studying the level of self-esteem among adolescents showed that $68.4 \%$ of the students in the sanatorium school showed a low level of self-esteem, dissatisfaction with themselves and their achievements. Awareness of their capabilities and limitations associated with the disease affects the self-perception and self-esteem of adolescents.

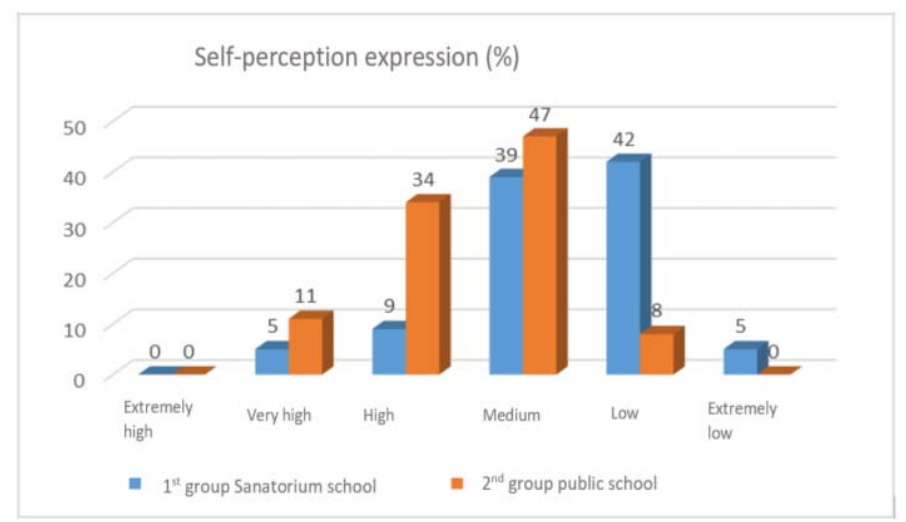

Fig. 2. Self-perception expression in groups of children attending a sanatorium school and a public school

There are clear differences in the expression of self-esteem among young people, the greatest differences being in the lower level of self-esteem, with $42 \%$ of young people in the sanatorium school having a negative view of themselves and their abilities, affecting their psychological well-being and health.

The Mann-Whitney U-test was used to identify significant differences in the expression of self-concept components among adolescents in different social environments.

The study of the reliability of differences in the expression of self-concept components in two groups of adolescents in different social environments showed that the differences in such scales as - "anxiety", "appearance, physical attractiveness", "communication", "selfconfidence", the general level of self-esteem are in the zone of significance. This indicates that the expression of these self-concept components is statistically different.

In the next stage of the empirical study, using the L.I. Wasserman, E.E. Malkova method of multidimensional anxiety assessment, anxiety spectrum disorders in adolescents in different social environments were studied.

The level of general anxiety, reflected in the adolescent's general level of recent anxiety related to self-esteem, self-confidence and perspective-taking, varied among the groups of adolescents studied. 
Diagnostic results showed that adolescents from public school have primarily average (normative) and low levels of anxiety, amounting to $70 \%$ of adolescents, about a quarter of adolescents from this group have high and 6\% very high levels of anxiety.

More than a third of the adolescents attending the residential school showed an average level of anxiety, the ability to control their emotions and behaviour in a stressful situation. $58 \%$ of adolescents in this group showed high and very high levels of anxiety, indicating their psycho-emotional dysfunction and low stress tolerance.

A study of anxiety in relationships with peers showed that there was also variation in the intensity of this indicator on this scale. Adolescence is characterised by an increased need to communicate with peers, including peers of the opposite sex.

Adolescents in public schools are more confident in their relationships with their peers and do not experience any difficulties.

Teenagers attending the residential school (65\%) experience some difficulties in communicating with their peers, perhaps the isolated environment of the school and restricted activities affect the nature of communication with peers and increase the level of communication anxiety.

A study of anxiety levels related to the assessment of others showed that adolescents with somatic diseases were significantly more sensitive to the opinions of others than their peers in mainstream schools. A very high level of anxiety was found in $19 \%$ of adolescents, and $42 \%$ had a high level of anxiety due to the possible negative assessment of their behaviour and personality by others. More than half of the adolescents in public schools have no anxiety in relation to the opinions of others, and $7 \%$ have a high level of anxiety about the opinions of others.

Thus, we can conclude that somatically challenged adolescents have different general and self-expression anxiety compared to adolescents in public schools. However, the digital environment provides some rehabilitative resources in this respect, with the necessary control of constructive navigation in the digital environment.

\section{Results discussion}

Research by Russian psychologists has shown that students with low health status have the following psychological characteristics: distractibility, rapid exhaustion, decreased pace of activity and work capacity.

Thus, we can establish the presence of certain risks in the subjective determination of the adolescents' socialization with low status of somatic health: increased anxiety, isolation, doubts in their abilities, problems with self-control over emotional state, insufficient satisfaction with the developmental situation. The outlined points should be taken into account when modelling psychological support programs for successful socialization of adolescents with low status of somatic health, taking into account the peculiarities of interaction with the digital environment.

The socialisation of an adolescent with reduced somatic health status in modern education is determined not only by the nature of the social and digital environment, but also by the inner position and attitude of the individual towards that environment.

Among the determinants of neurotic symptoms in the response to disease in adolescents are deficit attitudes towards their physical self, changes in self-esteem, various transformations of self-consciousness, individual experiences of interaction with self and others, socialisation conditions, degree of personal maturity, individual characteristics [6].

The main incentive for communication in adolescence is the desire to be, to take one's place among peers; the desire for independence and the recognition of the value of one's personality, here the scope is widened by the information space. 
Adolescents have a strong need to belong to a group, it is important for them to be accepted, to be in good relationships with peers and adults. The demands of groups in the information space can be very different, causing additional socialisation risks and potentially manifesting in certain types of deviant behaviour.

The modern social development context in itself generates difficulties in adolescent self-determination and a contradiction between the need for communication and heightened conflict, between desires and limitations associated with the course of the illness. The somatic problem exacerbates these difficulties and contributes to the emergence of negative personal reactions, especially in stressful, frustrating situations. It is the somatic weakness that generates a feeling of insecurity, and an inability to control the situation, a sense of helplessness. The results can be explained by the characteristics of the disease. With a longterm and unfavourable progression, the formation of neurotic personality traits can be observed. Adolescents with somatic diseases who attend the sanatorium school are more likely to have doubts about the success of their future plans, to be more conflicted internally and to have unstable perceptions of their popularity among their peers. They underestimate their level of communicative competence, have doubts about their appearance and physical attractiveness, have certain doubts about their physical appearance, demonstrate lower levels of self-esteem, dissatisfaction with themselves and their achievements, obstacles in the development of independence and increased vulnerability. Therefore, this category of adolescents needs psychological support in developing information competence and a culture of safe interaction in the digital environment.

\section{Conclusion}

The psychological resource of different formats for determining the model of socialisation of an adolescent with reduced somatic health status is determined by the positive, supportive nature of relationships, effective organisation of activities, constructive style of relationships, the presence of opportunities for self-realisation and growth. The risks of modern pedagogical systems in the digital educational environment, in the context of determining the socialization of somatically impaired adolescents, include the following points: unsupervised communication circles, unclear system of requirements, deficient functional-role communication, adolescents' desire to get approval at any cost, lack of scientifically grounded technological programs of psychological support.

These empirical research findings should be taken into account in the design of psychological support programmes for the successful socialisation of adolescents with reduced somatic health status.

\section{References}

1. S.A. Arakcheeva, M.I. Rozhkov, Social and pedagogical support for adolescents' selfdevelopment in a sanatorium boarding school, Social Pedagogy in Russia. Sciencemethodical journal, 6, 39-42 (2015)

2. S.A. Wildgrube, E.V. Kramarenko, Peculiarities of self-perception in adolescents with cardiovascular pathology, Bulletin of Emergency and Reconstructive Surgery, 4(2), 23 34 (2019)

3. N.A. Gadzhieva, M.I. Akhmedova, A.T. Pasha. Main problems of inclusive education and ways to solve them, Science and reality, 4(1), 49-53 (2020)

4. A.V. Grishina, I.V. Abakumova, I.V. Danchenko, Internet-blogs as a factor of career choice initiation by Russian schoolchildren, World of Science. Pedagogy and Psychology, 7, 6 (2019) 
5. L.Y. Zhilina, Difficulties and problems of professional self-determination of minors with somatic impairment, Science and education: problems, ideas, innovations, 4(7), 914 (2018)

6. E.V. Zakharova. Social frustration as a maladaptive factor in the development of children and adolescents with tuberculosis infection, Living Psychology, 5(4), 311-328 (2018)

7. V.I. Makarova, A.N. Pavlova, A.I Makarova. Risk factors affecting adolescent health in Russia and the USA: A literature review, Human Ecology, 7, 40-46 (2020)

8. T.I. Mironova, N.P. Fetiskin. Factors of latent stressogenesis and psychoprotection mechanisms in children with somatic abnormalities, Bulletin of Kostroma State University. Series: Pedagogy. Psychology. Sociokinetics, 22(4), 151-156 (2016)

9. V.V. Prokhorova, E.M. Kobozeva, O.N. Kolomyts, Innovative methods and forms of learning as determinants of learning quality improvement, Education and Law, 6, 198202 (2016)

10. A.A. Sadykova, K.A. Sultanova, S.K. Karakpaeva, Inclusive education as one of the main directions of reform in the education system, Research and Practice Studies, 22(25), 106-109 (2020)

11. N.A. Stepanova, A.V. Kuzmina. Features of socio-psychological adaptation of somatically impaired schoolchildren, Bulletin of Science and Education, 53, 68-70 (2018)

12. N.N. Sheshukova, E.N. Sinyavina, Psychological support for the personal development of adolescents studying in a boarding school, Scientific-Methodical Electronic Journal Concept, 8, 116-122 (2016)

13. A.R. Drozdikova-Zaripova, N.Y. Kostyunina. Helping Adolescents with Health Problems to Become Socially Competent, International Journal of Environmental and Science Education, 11(6), 1079-1090 (2016)

14. M. Fridh, et al., Subjective health complaints and exposure to peer victimization among disabled and non-disabled adolescents: A population-based study in Sweden, Scandinavian journal of public health, 46(2), 262-271 (2018)

15. N.J. Parr, et al. Peer emotion socialization and somatic complaints in adolescents Journal of Adolescence, 50, 22-30 (2016) 